\title{
Dual Gold-Catalyzed Three-Component Reaction: the Efficient Synthesis of Indene-Fused Esters, Acids and Lactones through Gold Vinylidene Intermediates
}

\author{
Congjun $\mathrm{Yu}^{[\mathrm{a}]}$, Xiaodong Ma ${ }^{[\mathrm{a}]}$, Bin Chen ${ }^{[\mathrm{a}]}$, Bencan Tang ${ }^{[\mathrm{c}]}$, Robert S. Paton ${ }^{[\mathrm{b}] \star}$, and Guozhu Zhang ${ }^{[\mathrm{a}] *}$
}

Abstract: A dual gold(I)-catalyzed three-component reaction has been developed to prepare indene-fused carboxylic acid derivatives from diynes, alcohols and pyridine- $\mathrm{N}$-oxide compounds in both interand intramolecular fashion. Pyridine $\mathrm{N}$-oxides exhibit distinct selectivity compared to well-developed gold-catalyzed oxidative functionalization of alkyne in which a-oxo goldcarbene intermediates Experimental studies and DFT calculations support the double nucleophilic substitutions of the gold vinylidene intermediate.

\section{Introduction}

Multi-component transformations have emerged as powerful tools in organic synthesis due to their innate simplicity, efficiency and elegance. ${ }^{[1]}$ Among those, transition metal-catalyzed threecomponent reactions attract broad research interests as they invoke unique reactivities. ${ }^{[2]}$ Obviously, the development of novel multi-component reactions for efficient synthesis of synthetically useful molecular scaffolds remains of high demand.

(1)

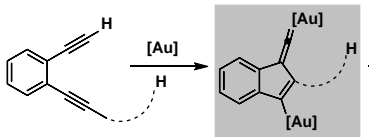

(2)
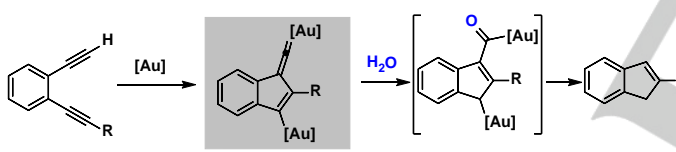

(3)
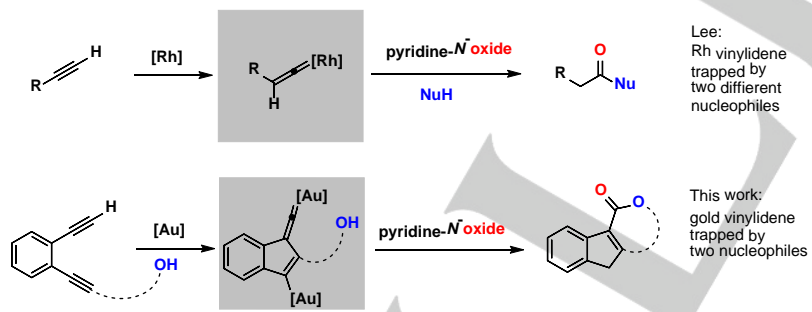

The past decade has seen rapid developments in the area of homogeneous gold catalysis. ${ }^{[3]}$ In several early studies, gold

[a] C. Yu, X. Ma, B. Chen, Prof. Dr. G. Zhang

State Key Laboratory of Organometallic Chemistry

Shanghai Institute of Organic Chemistry, Chinese Academy of

Sciences, 345 Lingling Road, Shanghai 200032 (P. R. China)

E-mail: quozhuzhang@sioc.ac.cn

[b] Prof. R. Paton

Chemistry Research Laboratory, University of Oxford, 12 Mansfield Road, Oxford OX1 3TA, E-mail: robert.paton@chem.ox.ac.uk

[c] Dr. Bencan Tang

Department of Chemical and Environmental Engineering, Faculty of Science and Engineering, University of Nottingham Ningbo China, Ningbo315100, China

Supporting information for this article is given via a link at the end of the document.((Please delete this text if not appropriate)) vinylidenes have been proposed as reactive intermediates, ${ }^{[4-8]}$ which underwent facile $\mathrm{C}-\mathrm{H}$ or $\mathrm{Nu}-\mathrm{H}$ insertion [eq. (1)]. Only a few reports appeared in which a gold vinylidene is trapped with one nucleophile such as water ${ }^{[9]}$ or methoxy group ${ }^{[10]}$ [eq. (2)]. In line with our interests in exploring new reactivities of $\mathrm{Au}$ vinylidene, we continue to be inspired by other metal vinylidene complexes such as $\mathrm{Ru}, \mathrm{Rh}$, and $\mathrm{W}^{[11]}$ In 2013, Lee and coworkers reported an elegant pyridine $\mathrm{N}$-oxide mediated oxidation of Rhodium vinylidene to ketene ${ }^{[12]}$ leading to a variety of carboxylic acid derivatives [eq. (3)]. We wonder if similar strategies could be applied to gold vinylidene. Herein we report that pyridine $\mathrm{N}$-oxide indeed could serve as a unique oxygen transferring agent to gold vinylidene, giving highly functionalized indene-fused esters, acids and lactones. Temporary mechanistic studies and theoretical calculations suggest ketene formation is a viable reaction pathway [eq. (4)]

\section{Results and Discussion}

Our study began with evaluating the feasibility of the reaction inducing ethanol addition to dialkyne with commercially available pyridine $\mathrm{N}$-oxide as the oxygen transferring agent in the presence of IPrAuNTf 2 (IPr=1,3-bis(diisopropylphenyl)imidazol2-ylidene). To our delight, the desired indene fused ester product was indeed isolated. After numerous trials, IPrAuNTf $\mathrm{I}_{2}(5$ mmol\%), 3,5-dichloropyridine $\mathrm{N}$-oxide(1.5 equiv), $\quad 1,2-$ dichloroethane and ethanol $(1: 1,0.03 \mathrm{M})$ at $70{ }^{\circ} \mathrm{C}$ was the optimized reaction conditions, giving $\mathbf{2 a}$ in $88 \%$ yield [eq. (5)]
(5)

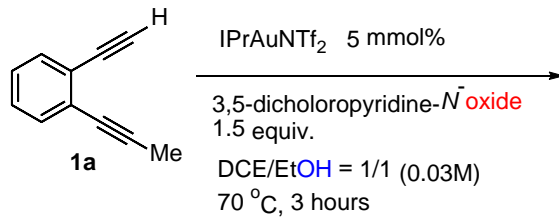

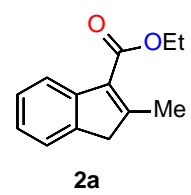

isolated yield: $88 \%$
With the optimal reaction conditions in hand, the substrate scope was promptly investigated by examining various alkynes and alcohols nucleophiles. As summarized in Table 1, almost all natures of aliphatic alcohols, such as primary, secondary and tertiary alcohols are good substrates for the three-component oxygenative cyclization reactions $(\mathbf{2 a}-\mathbf{2 h})$. The reaction also tolerated benzylic- and allylic alcohol (2i-2j). Pharmaceutically interesting mono-fluoro and trifluoromethyl groups didn't interfere with the reaction (2k-2I). A synthetically useful acetone functionality was also successfully engaged in the addition reaction $(\mathbf{2 m})$. The variations on the diyne aromatic backbone were also briefly investigated. Substituents such as $\mathrm{Me}, \mathrm{Cl}$, and OMe on the benzene ring were well tolerated $(2 n-2 p)$. When the methyl was changed to other groups like bromine and cyclopropyl groups, the reactions worked as well (2q-2r). In order to broaden the universality of this reaction, many other nucleophiles have been explored. We were pleased to find that 
water and ethyl acetoacetate were also reactive nucleophiles, the later giving $\mathbf{2 v}$ in vinyl ester form. However, amine and sulfur alcohol were not the effective nucleophiles under current reaction conditions.

Table 1. Intermolecular reactions of gold vinylidenes. ${ }^{[a]}$

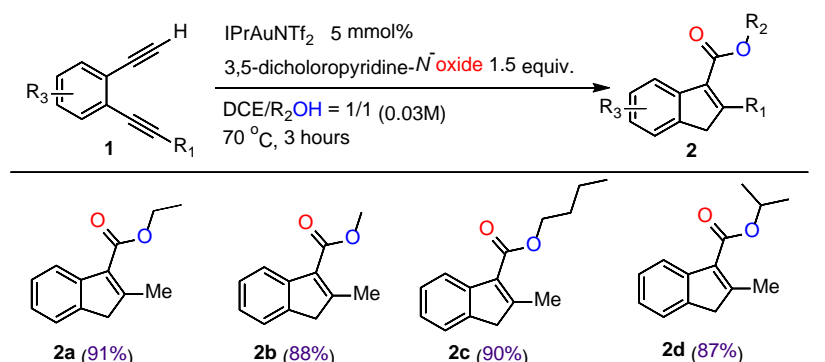<smiles>CC1=C(C(=O)OCc2ccccc2)Cc2cccc(CCCOC(=O)C3C(C)=C(C(=O)OCCCc4ccccc4)c4ccccc43)c21</smiles><smiles>CC(C)=CCC/C(C)=C/COC(=O)C1=C(C)Cc2ccccc21</smiles>
$2 \mathbf{i}(81 \%)$<smiles>CC(=O)COC(=O)C1=C(C)Cc2ccccc21</smiles>

$2 \mathbf{j}(63.6 \%)$ 2l $(75 \%)$<smiles>CCOC(=O)C1=C(C)Cc2ccc(C)cc21</smiles><smiles>CCOC(=O)C1=C(Br)Cc2ccccc21</smiles><smiles>CC1=C(C(=O)OC(C)(C)C)c2ccccc2C1</smiles>

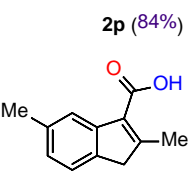<smiles>CCOc1ccc2c(c1)CC(C)=C2C(=O)O</smiles><smiles>C/C=C\CCCCC</smiles>

2s $(50 \%)^{[b]}$ $2 \mathbf{t}(60 \%)^{[b]}$ $2 \mathbf{u}(41 \%)^{[b]}$

2v $(58 \%)$

[a] Yields of isolated product. [b] About 10\% diynes were recovered.

Lactones are a diverse group of natural products with a wide range of biological activity. We envisioned that an intramolecular version of our protocol might offer an exquisite approach to the lactone scaffold. We first subjected $\mathbf{3} \mathbf{a}^{\prime}$ to the optimized conditions, however, a known furan was isolated, ${ }^{[5 a]}$ presumably due to the downstream aromatization once the gold vinylidene is trapped by the secondary alcohol [eq. (6)].

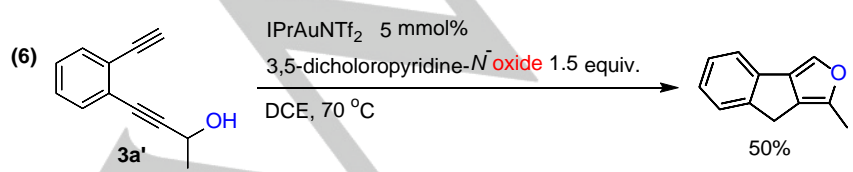

To inhibit the aromatization, the tertiary alcohol $\mathbf{3 a}$ was prepared and indeed gave the indene-fused lactone product under the established intermolecular reaction conditions.

Condition optimization finally led to the isolated product $\mathbf{4 a}$ in $82 \%$ yield (Table 2). The scope and limitations of this intramolecular oxygenative lactonization was subsequently investigated (Table 2). Tertiary alcohols with different ring size and skeleton reacted well (4b-4d). The benzene backbone could be substituted with $\mathrm{CF}_{3}$, Me and $\mathrm{Cl}$ groups $(\mathbf{4 e - 4 g})$. To our delight, the noncyclized tertiary alcohols were successfully engaged in the oxidative lactonization (4h-4k). The further enhanced synthetic utility of this methodology was demonstrated in the preparation of seven-membered lactones which represents another important molecular motif (4I-4n). Unfortunately, our attempts to generate six-membered or even larger macrolactones were not successful.

Table 2. Intramolecular reactions of gold vinylidenes. ${ }^{[a]}$
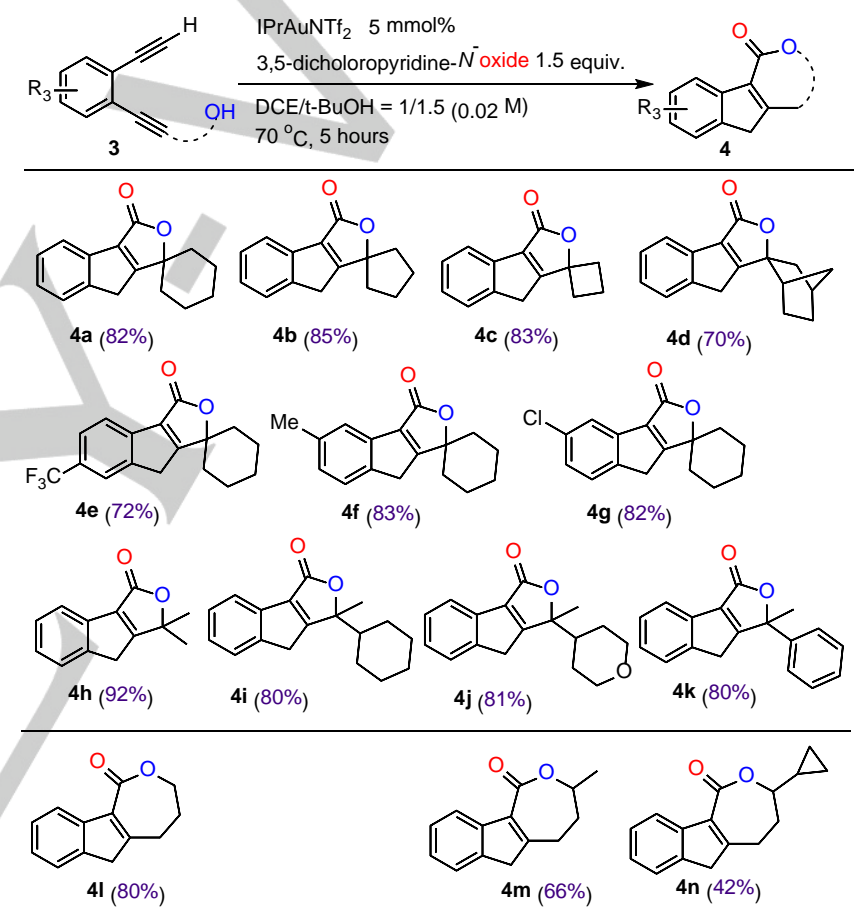

[a] Yields of isolated product.

Next we turned our attention to the mechanistic studies. Several control experiments were carried out. When deuterated ethanol (EtOD) was used as a cosolvent, the methylene group of the product was deuterated by $95 \%$ [eq. (7)], which suggests a dual gold catalysis nature. Vinyl ethyl ether 6 could be isolated from the reaction in the absence of pyridine $\mathrm{N}$-oxide, no desired ester was observed from the reaction of 6 [eq. (8)]. This result indictates the oxygen transfer from pyridine $\mathrm{N}$-oxide might occur first. 


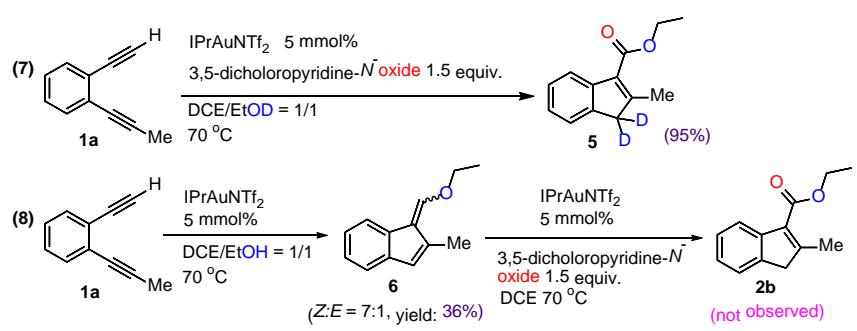

Therefore, a tentative mechanism is proposed (Scheme 1). The generation of gold vinylidene intermediate II initiates the reaction cascade. II can be trapped with pyridine $\mathrm{N}$-oxide as a nucleophile followed by leaving of the pyridine leading to species IV. Then a key ketene $\mathbf{V}$ formation, ${ }^{[11 i, 12]}$ nucleophilic addition of alcohol and demetalation provides $\mathbf{2} \mathbf{a}$.

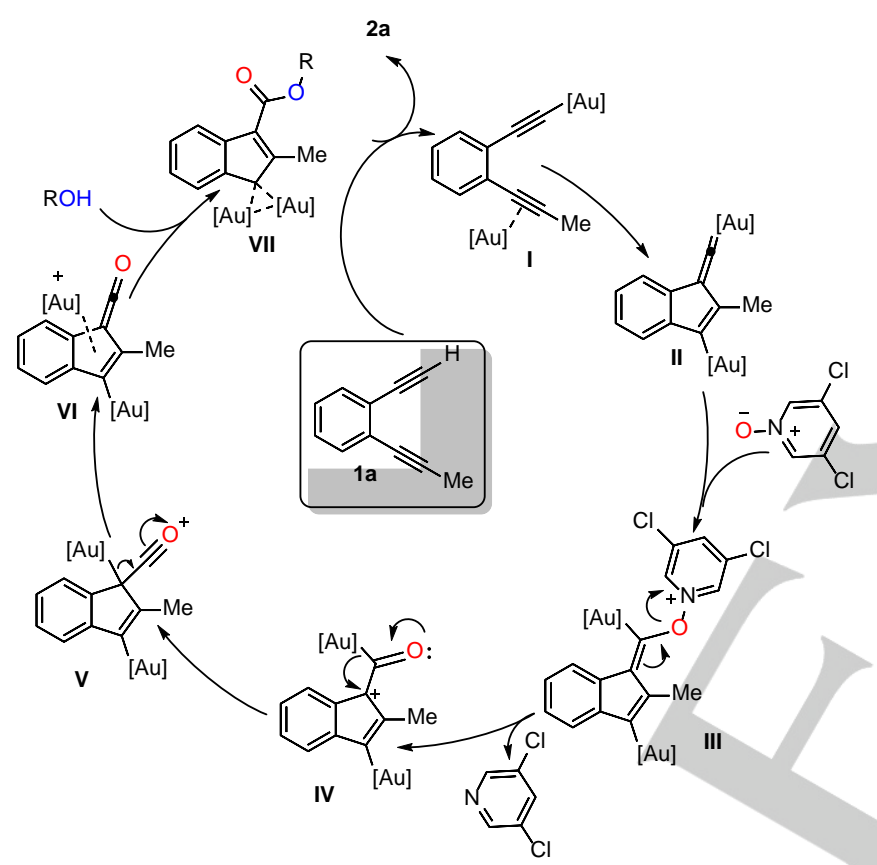

Scheme 1. Proposed mechanism for dual gold catalysed threecomponent reaction.

In order to gain further insight and to support our outlined mechanism, we performed DFT calculations to investigate the energetics of the above proposed mechanism, the geometry optimizations and transitions state searches were performed on the B3LYP ${ }^{[13]}$ level with $6-31+\mathrm{G}(\mathrm{d})$ basis set for $\mathrm{C}, \mathrm{H}, \mathrm{N}, \mathrm{O}, \mathrm{Cl}$ atoms and LANL2DZ ${ }^{[14]}$ with relativistic effective core potentials for gold, as B3LYP has recently been shown to give reasonable energy and geometry predictions for homogeneous gold catalysis $^{[15]}$ and these besis sets were recenly proved to be suitable for the geometry predictions for similiar systems involving gold atoms. ${ }^{[16]}$ Single point calculations were performed at the M06 level with a mixed basis set of SDD for gold [17] and $6-311+G(d, p)$ for all other atoms, as this was approved to provide reliable energy evaluation for similiar gold catalysis. ${ }^{[18]}$ Solvation energy corrections were calculated using SMD model and with dichloroethane as solvent. All calculations were performed with Gaussian 09 program pachage. ${ }^{[19]}$ All transition states were confirmed by intrinsic reaction coordinate
(IRC) toward a set of pre- and postreaction complexes. ${ }^{[20]}$ Computed structures are displayed with CYLview. ${ }^{[21]}$

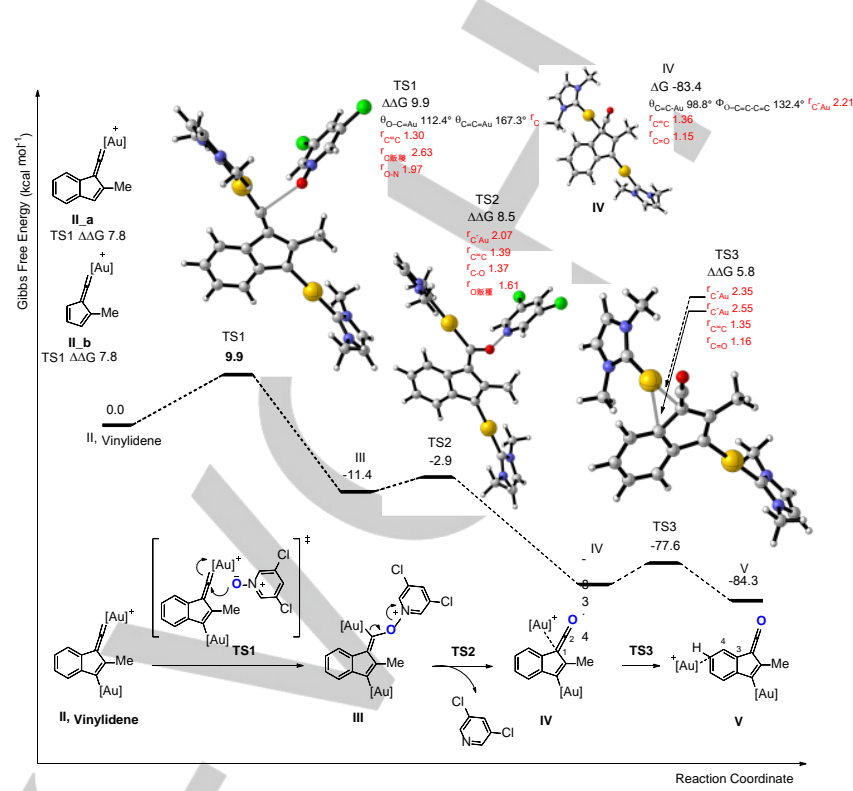

Figure 1. Computed free energy profile for 3,5-dichloro pyridine $\mathrm{N}$-oxide reacting with gold vinylidene.

The calculation was started from gold vinylidene intermediate II. ${ }^{[5 a, 5 h, 18]}$ The activation barrier for the nucleophilic attack by pyridine $\mathrm{N}$-oxide was calculated as $9.9 \mathrm{kcal}$ mol-1 (see Figure 1, TS1). This is comparable to the reported intramolecular $\mathrm{C}\left(\mathrm{sp}^{3}\right)-\mathrm{H}$ insertion reaction in II for which the calculated free energy barrier was $9.2 \mathrm{kcal} / \mathrm{mol} .{ }^{[5 a, 5 \mathrm{~h}]}$ The reaction was also investigated with vinylidene intermediate analogues II_a and II_b (Figure 1), and the activation barriers were found to be 7.8 and $7.7 \mathrm{kcal}$ mol-1 respectively, which were lower than that for II itself. In transition state TS1, the bond length for the newly formed $\mathrm{C}-\mathrm{O}$ interaction is $2.63 \AA$. The angle of $\mathrm{C}=\mathrm{C}=\mathrm{Au}$ is $167.3^{\circ}$, bending by $12.7^{\circ}$ from the linear structure in vinylidene II. This leads to the formation of intermediate III, which then undergoes decomposition to form an intermediate IV with a barrier of $8.5 \mathrm{kcal} \mathrm{mol}^{-1}$ (see TS2). In the intermediate IV, $\mathrm{Au}$ is complexed to $\mathrm{C} 1$ carbon center directly, the $\mathrm{C} 1=\mathrm{C} 2$ bond has a bond length of $1.36 \AA, C 2=0$ bond length of $1.15 \AA$, and C1-Au bond length of $2.21 \AA$ (Figure 1, IV). Moreover, the bond angle for $\mathrm{C} 2-\mathrm{C} 1-\mathrm{Au}$ is $98.8^{\circ}$, the $\mathrm{O}=\mathrm{C}=\mathrm{C}$ bond is out of the phenyl cyclopatene plane by $47.6^{\circ}$. The bond lengths of the $\mathrm{O}=\mathrm{C}=\mathrm{C}$ moiety are similar to those for a ketene structure ${ }^{[22]}$ therefore we believe the cleavage of the $\mathrm{O}-\mathrm{N}$ bond in III can lead to the formation of ketene IV directly. The free energy of IV is much lower (by $72 \mathrm{kcal} \mathrm{mol}^{-1}$ ) than III, making this a very favorable process. The Au complex in IV was found to be able to migrate to benzene ring through $\mathrm{C} 3$ and $\mathrm{C} 4$ to form $\mathbf{V}$ directly. This process happens through transition TS3, with a very low activation barrier $5.8 \mathrm{kcal} \mathrm{mol}^{-1}$. This serves as one of the intermediate structures for gold slippage in the $\pi$ system, and it can be transferred into gem-diaurated species VI (Scheme 1), directly or after nucleophilic attack by alcohol, which, followed by 
gold and hydrogen exchange with $1 \mathbf{a}$, completes the catalytic cycle.

\section{Conclusions}

In summary, we were able to realize a dual gold-catalyzed three-component coupling relying on a new reactivity of gold vinylidene intermediate. Pyridine $\mathrm{N}$-oxide serve as unique oxygen transfer agent with a distinct selectivity comparing to that in $\alpha$-oxo gold carbene chemistry. The oxygenative cyclized 1,1difunctionalization could readily take place in both inter- and intramolecular settings, leading to a variety of indene-fused esters, acids and lactones. Further investigation concerning gold vinylidene is currently underway in our laboratory.

\section{Experimental Section}

General Procedure for the Synthesis of compound 2: In a flask, 1.0 equiv. of 1 is dissolved in a mixing solvent consisting of 1,2 dichloroethane and $\mathrm{R}_{2} \mathrm{OH}(\mathrm{V} / \mathrm{V}=1 / 1,0.03 \mathrm{M})$, then $5 \mathrm{mmol} \%$ of $\mathrm{IPrAuNTf}_{2}$ and 1.5 equiv. 3, 5-dicholoropyidine- $\mathrm{N}$-oxide are added. The reaction mixture is stirred at $70^{\circ} \mathrm{C}$ until complete conversion is detected by TLC ( $3 \mathrm{hrs}$ ). Then, it is evaporated and purified by flash column chromatography (hexane/ethyl acetate $=20 / 1$ ) to afford 2 .

\section{Acknowledgements}

Acknowledgements Text. We are grateful to NSFC-21421091, XDB20000000, the "Thousand Plan" Youth program, State Key Laboratory of Organometallic Chemistry, Shanghai Institute of Organic Chemistry, Chinese Academy of Sciences. We acknowledge the use of the EPSRC UK National Service for Computational Chemistry Software (CHEM773) in carrying out this work. We are also grateful for access to the University of Nottingham High Performance Computing Facility.

Keywords: dual gold catalysis• gold vinylidenes $\bullet$ threecomponent $\bullet$ esters $\bullet$ lactones

[1] a) J. Zhu, Q. Wang, M. Wang, Eds. Multicomponent Reactions in Organic Synthesis; Wiley-VCH Verlag GmbH \& Co. KGaA: Weinheim, Germany, 2015. b) Cioc, R. C.; Ruijter, E.; Orru, R. V. A. Green Chem. 2014, 16, 2958-2975.

[2] a) H. Clavier, H. Pellissier, Adv. Synth. Catal. 2012, 354, 3347-3403; b) G. Abbiati, E. Rossi, Beilstein J. Org. Chem. 2014, 10, 481-513.

[3] a) A. S. K. Hashmi, G. J. Hutchings, Angew. Chem. 2006, 118, 80648105; Angew. Chem. Int. Ed. 2006, 45, 7896-7936; b) L. Zhang, J. Sun and S. A. Kozmin, Adv. Synth. Catal. 2006, 348, 2271-2296; c) D. J. Gorin, F. D. Toste, Nature 2007, 446, 395-403; d) A. S. K. Hashmi, M. Rudolph, Chem. Soc. Rev. 2008, 37, 1766-1775; e) E. Jimenez-Nunez and A. M. Echavarren, Chem. Rev. 2008, 108, 3326-3350; f) Z. Li, C. Brouwer and C. He, Chem. Rev. 2008, 108, 3239-3265; g) A. Arcadi, Chem. Rev. 2008, 108, 3266-3325; h) D. J. Gorin, B. D. Sherry and F. D. Toste, Chem. Rev. 2008, 108, 3351-3378; i) A. Fürstner, Chem. Soc Rev. 2009, 38, 3208-3221; j) S. Bertelsen, K. A. Jørgensen, Chem. Soc. Rev. 2009, 38, 2178-2189; k) T. C. Boorman, I. Larrosa, Chem. Soc. Rev. 2011, 40, 1910-1925; I) S. P. Nolan, Acc. Chem. Res. 2011,
44, 91-100; m) M. Bandini, Chem. Soc. Rev. 2011, 40, 1358-1367; n) M. Rudolph, A. S. K. Hashmi, Chem. Commun. 2011, 47, 6536-6544. o) F. López, J. L. M. Beilstein, J. Org. Chem. 2011, 7, 1075-1094; p) B. Biannic, A. Aponick, Eur. J. Org. Chem. 2011, 6605-6617; q) C. Obradors, A. M. Echavarren, Chem. Commun. 2014, 50,16-28; r) J. Xie, C. Pan, A. Abdukader, C. Zhu, Chem. Soc. Rev. 2014, 43, 5245-5256.

[4] a) I. V. Seregin and V. Gevorgyan, J. Am. Chem. Soc. 2006, 128 12050-12051; b) P. H. Cheong, P. Morganelli. M. R. Luzung, K. N Houk, and F. D. Toste, J. Am. Chem. Soc. 2008, 130, 4517-4526; c) A. S. K. Hashmi, I. Braun, M. Rudolph, F. Rominger, Organometallics 2012, 31, 644-661; d) M. M. Hansmann, F. Rominger, A. S. K. Hashmi, Chem. Sci. 2013, 4, 1552-1559; e) S. Mader, L. Molinari, M. Rudolph, F. Rominger, A. S. K. Hashmi Chem. Eur. J. 2015, 21, 3910-3913; f) M. Wieteck, M. H. L. Vilhelmsen, P. Nçsel, J. Schulmeister, F. Rominger, M. Rudolph, M. Pernpointner, and A. S. K. Hashmi, Adv. Synth. Catal. 2016, 358, 1449-1462.

[5] a) L. Ye, Y. Wang, D. H. Aue, and L. Zhang, J. Am. Chem. Soc. 2012 134, 31-34; b) A. S. K. Hashmi, I. Braun, P. Nösel, J. Schadlich, M. Wieteck, M. Rudolph, F. Rominger, Angew. Chem. 2012, 124, 4532 4536; Angew. Chem. Int. Ed. 2012, 51, 4456-4460; c) A. S. K. Hashmi, M. Wieteck, I. Braun, P. Nösel, L. Jongbloed, M. Rudolph, F. Rominger, Adv. Synth. Catal. 2012, 354, 555-562; d) A. S. K. Hashmi, I. Braun, M. Rudolph, F. Rominger, Organometallics 2012, 31, 644-661; e) A. S. K. Hashmi, I. Braun, P. Nösel, J. Schädlich, M. Wieteck, M. Rudolph, F. Rominger, Angew. Chem. 2012, 124, 4532-4536; Angew. Chem. Int Ed. 2012, 51, 4456-4460; f) A. S. K. Hashmi, M. Wieteck, I. Braun, M. Rudolph, F. Rominger, Angew. Chem. 2012, 124, 10785-10789; Angew. Chem. Int. Ed. 2012, 51, 10633-10637; g) A. S. K. Hashmi, T. Lauterbach, P. Nösel, M. H. Vilhelmsen, M. Rudolph, F. Rominger, Chem. Eur. J. 2013, 19, 1058-1065; h) M. M. Hansmann, M. Rudolph, F. Rominger, A. S. K. Hashmi, Angew. Chem. 2013, 125, 2653-2659; Angew. Chem. Int. Ed. 2013, 52, 2593-2598; i) P. Nösel, T. Lauterbach, M. Rudolph, F. Rominger, A. S. K. Hashmi, Chem. Eur. J. 2013, 19, 8634-8641; j) M. M. Hansmann, S. Tsupova, M. Rudolph, F. Rominger, A. S. K. Hashmi, Chem. Eur. J. 2014, 20, 2215-2223; k) M. H. Vilhelmsen, A. S. K. Hashmi, Chem. Eur. J. 2014, 20, 1901-1908; I) M. Wieteck, Y. Tokimizu, M. Rudolph, F. Rominger, H. Ohno, N. Fujii, A. S. K. Hashmi, Chem. Eur. J. 2014, 20, 16331-16336; m) Y. Tokimizu, M. Wieteck, M. Rudolph, S. Oishi, N. Fujii, A. S. K. Hashmi, H. Ohno, Org. Lett. 2015, 17, 604-607.

[6] a) V. Mamane, P. Hannen, A. Fürstner, Chem. Eur. J. 2004, 10, 45564575; b) P. Moran-Poladura, S. Suarez-Pantiga, M. Piedrafita, E. Rubio, J. M. Gonzalez, J. Organomet. Chem. 2011, 696, 12-15; c) P. MoranPoladura, E. Rubio, J. M. Gonzalez, Beilstein J. Org. Chem. 2013, 9, 2120-2128.

[7] J. Bucher, T. Wurm, K. S. Nalivela, M. Rudolph, F. Rominger, A. S. K. Hashmi, Angew. Chem. 2014, 126, 3934-3939; Angew. Chem. Int. Ed. 2014, 53, 3854-3858.

[8] Y. Wang, M. Zarca, L. Gong, L. Zhang, J. Am. Chem. Soc. 2016, 138 7516-7519.

[9] J. Bucher, T. Stößer, M. Rudolph, F. Rominger, A. S. K. Hashmi, Angew. Chem. 2015, 127, 1686-1690; Angew. Chem. Int. Ed. 2015, 54, 1666-1670.

[10] C. Yu, B. Chen, T. Zhou, Q. Tian, G. Zhang, Angew. Chem. 2015, 127, 11053-11057; Angew. Chem. Int. Ed. 2015, 54, 10903-10907.

[11] a) M. I. Bruce, Chem. Rev. 1991, 91, 197-257; b) F. E. McDonald, Chem. Eur. J. 1999, 5, 3103-3106; c) C. Bruneau, P. H. Dixneuf, Acc. Chem. Res. 1999, 32, 311-323; d) C. Bruneau, P. H. Dixneuf, Angew. Chem. 2006, 118, 2232-2260; Angew. Chem. Int. Ed. 2006, 45, 21762203; e) J. A. Varela, C. Saa, Chem. Eur. J. 2006, 12, 6450-6456; f) C. Bruneau, P. H. Dixneuf, Eds. Wiley-VCH: Weinheim, Germany, 2008; g) B. M. Trost, A. McClory, Chem. Asian J. 2008, 3, 164-194; h) J. M. Lynam, Chem. Eur. J. 2010, 16, 8238-8247; i) Y. Wang, Z. Zheng, L. Zhang, Angew. Chem. 2014, 126, 9726-9730; Angew. Chem. Int. Ed. 2014, 53, 9572-9576. 
[12] I. Kim, C. Lee, Angew. Chem. 2013, 125, 10207-10210; Angew. Chem. Int. Ed. 2013, 52, 10023-10026.

[13] a) C. Lee, W. T. Yang, R. G. Parr, Phys. Rev. B: Condens. Matter 1988 , 37, 785-789. (b) A. D. Becke, J. Chem. Phys. 1993, 98, 5648-5652.

[14] a) W. R. Wadt, P. J. Hay, J. Chem. Phys. 1985, 82, 284; b) K. A. Peterson, C. Puzzarini, Theor. Chem. Acc. 2005, 114, 283; c) D Figgen, G. Rauhut, M. Dolg, H. Stoll, Chem. Phys. 2005, 311, 227.

[15] a) O. N. Faza, R. Á. Rodríguez, S. C. López, Theor. Chem. Acc. 2011 128, 647. For the comparison of fully relativistic DHF-SCF, DFT/B3LYP and GF, see: b) M. Pernpointner, A. S. K. Hashmi, J. Chem. Theory Computation 2009, 5, 2717.

[16] a) R. S. Paton, F. Maseras, Org. Lett., 2009, 11, 2237-2240; b) P. H. Cheong, P. Morganelli, M. R. Luzung, K. N. Houk, F. D. Toste, J. Am. Che,. Soc. 2008, 12, 4517-4526; c) E. L. Noey, Y. Luo, L. Zhang, and K. N. Houk, J. Am. Chem.Soc. 2012, 134, 1078-1084; d) A.Ariafard, E.
Asadollah, M. Ostadebrahim, N. A. Rajabi and B. F. Yates, J. Am. Chem. Soc. 2012, 134, 16882-16890.

[17] M. Dolg, H. Stoll, H, Preuss, R. M. Pitzer, J. Phys. Chem. 1993, 97 5852.

[18] M. H. Larsen, K. N. Houk, and A. S. K. Hashmi, J. Am. Chem. Soc 2015, 137, 10668-10676;

[19] M. J. Frisch, et al., Gaussian 09, Revision D.01, Gaussian, Inc. Wallingford CT, 2009. See the Supporting Information for the full reference.

[20] a) H. P. Hratchian, H. B. Schlegel, J. Chem. Phys., 2004, 120, 9918; b) H. P. Hratchian, H. B. Schlegel, J. Chem. Theory Comput., 2005, 1, 61.

[21] CYLview, 1.0b; Legault, C. Y., Université de Sherbrooke, 2009 (http://www.cylview.org)

[22] C. E. Cannizzaro, K. N. Houk, J. Am. Chem. Soc. 2004, 126, 10992. 


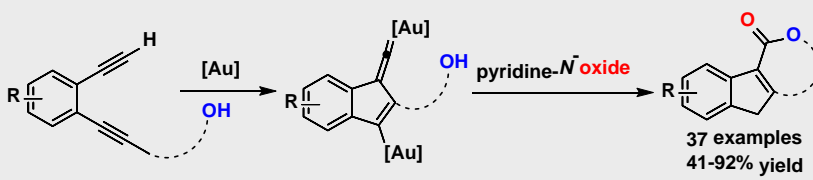

A dual gold(I)-catalyzed three-component reaction has been developed to prepare indene-fused carboxylic acid derivatives from diynes, alcohols and pyridine- $\mathrm{N}$ oxides in both inter- and intramolecular fashion. Pyridine $\mathrm{N}$-oxides exhibit unique reactivity and selectivity to oxidize the gold vinylidene. Experimental studies and DFT calculations support the key ketene formation.

*one or two words that highlight the emphasis of the paper or the field of the study

\section{Au Catalysis*}

Congjun Yu[a], Xiaodong $\mathrm{Ma}^{[a]}$, Bin Chen ${ }^{[a]}$, Bencan Tang ${ }^{[c]}$, Robert S.

Paton $^{[b] *}$, Guozhu Zhang ${ }^{[a] *}$

\section{Page No. - Page No.}

Dual Gold-Catalyzed ThreeComponent Reaction: the Efficient Synthesis of Indene-Fused Esters, Acids and Lactones through Gold Vinylidene Intermediates 